\title{
Synthesis and characterization of porous silica and polyaniline-porous silica composite materials with high surface area
}

\author{
U. S. Akhtar, ${ }^{1}$ M. K. Hossain, ${ }^{2}$ M. S. Miran, ${ }^{3}$ and M. Y. A. Mollah ${ }^{3 *}$ \\ ${ }^{1} I G C R T$, BCSIR, Dhaka-1205 \\ ${ }^{2}$ BCSIR Laboratories Dhaka, Dhaka-1205, Bangladesh \\ ${ }^{3}$ Department of Chemistry, University of Dhaka, Dhaka-1000, Bangladesh
}

\begin{abstract}
Porous silica materials were synthesized from tetraethyl orthosilicate (TEOS) using Pluronic P123 (non-ionic triblock copolymer, $\mathrm{EO}_{20} \mathrm{PO}_{70} \mathrm{O}_{20}$ ) as template under acidic conditions which was then used to prepare polyaniline (PAni) and porous silica composites (PAnisilica) at a fixed molar ratio. These materials were characterized by nitrogen adsorption-desorption isotherm measured by Barrett-JoynerHalenda (BJH) method and pore size distribution from desorption branch and surface area measured by the Brunauer-Emmett-Teller (BET) method, scanning electron microscopy (SEM), transmission electron microscopy (TEM), TEM-energy dispersive X-ray (EDX) and Fourier transform infrared (FT-IR) spectroscopy. The composite maintains its structure even after the polymerization and the polymer is dispersed on the inorganic matrix. The rod-like porous silica was about $1 \mu \mathrm{m}$ to $1.5 \mu \mathrm{m}$ long and on an average the diameter was in the range of 300 $500 \mathrm{~nm}$. The SEM and TEM images show well ordered $2 \mathrm{~d}$ hexagonal pore, high specific surface area $\left(850 \mathrm{~m}^{2} \mathrm{~g}^{-1}\right)$ and uniform pore size of ca. $6.5 \mathrm{~nm}$ in diameter. After incorporation of PAni inside the silica pore, framework of porous silica did not collapse and the surface area of the composite was as high as $434 \mathrm{~m}^{2} \mathrm{~g}^{-1}$ which was 5.5 time higher than our previous report of $78.3 \mathrm{~m}^{2} \mathrm{~g}^{-1}$. Due to shrinkage of the framework during the incorporation of aniline inside the silica, the pore diameter slightly increase to $7.5 \mathrm{~nm}$ but still showing Type IV isotherm and typical hysteresis loop H1 implying a uniform cylindrical pore geometry.
\end{abstract}

Keywords: Pluronic P123; Porous silica; SEM; TEM-EDX; Polyaniline-porous silica composite; BET surface area

\section{Introduction}

The synthesis of mesoporous silica and other mesoporous oxides with oligomers and polymers as templates have attracted considerable attention that led to the development of convenient synthesis pathways for materials with tailored porous structures and desirable morphologies. Different types of oligomeric and polymeric templates have already been employed in the synthesis of mesoporous oxides. It was first demonstrated that oligomers, such as alkyl poly- (ethylene oxide) and alkyl phenyl poly-(ethylene oxide) surfactants are facile supramolecular templates (Bagshaw et al 1995). The use of liquid-crystalline phases of oligomeric surfactants under acidic conditions allowed for the preparation of hexagonal (pore size of about $3.0 \mathrm{~nm}$ ) and cubic mesoporous silica (Attard et al 1995). The synthesis in neutral media afforded disordered mesoporous silica with large specific surface area and uniform pores up to about 2.0-5.0 nm (Bagshaw et al 1995).

Polyaniline (PAni) is one of the most studied conducting polymers, because it is chemically stable, easy to polymerize, the monomer is inexpensive and the doping process is reversible. PAni exists in different forms with emeraldine salt being the most conducting one (Djurado et al 2003). Due to its unique electrical and optical properties, PAni has several applications as active material in sensors (Xie et al 2002: Li et al 2009), in batteries (Baochen et al 1988) as anticorrosion coating, electromagnetic interference shielding (Faez et al 2000). However, its thermal and mechanical properties are inferior compared to other conventional polymers, thus many of its potential applications have not been completely explored (Zhang et al 2012). To improve such properties, attention has been focused on the preparation of PAni composites containing inorganic matrixes with an objective of the synergism of their properties (Wang et al 2011). Among the inorganic matrixes, ordered mesoporous silica (OMS), has been used for this purpose due to its high surface area (about $1000 \mathrm{~m}^{2} \mathrm{~g}^{-1}$ ), large pores (around 10.0 $\mathrm{nm}$ ), high mechanical and chemical stability, tunable porosity and easiness for functionalization (Zhao et al 1998). Recently, we have reported that PAni-silica composites exhibited higher surface energy and BET surface area than those of the bulk polymer studied and inverse gas chro-

\footnotetext{
*Corresponding author. e-mail: myamollah@hotmail.com
} 
matography (IGC) results indicated that prepared PAni-silica composites can be applicable as column materials to separate linear hydrocarbons in the range $\mathrm{C}_{5}-\mathrm{C}_{9}$ (Akhtar et al 2012). It is thus of interesting to prepare composite materials in combination with PAni and porous silica to improve the inherent properties of the composites for task-specific applications.

In continuation of our previous work we now report the preparation of porous silica material and PAni-porous silica composites and investigate their surface morphology and elemental analyses by SEM, TEM and TEM-EDX. The main focus of the present research has been on the nitrogen adsorption-desorption isotherm and pore size distribution and BET surface area along with molecular characterization of the composites by FT-IR.

\section{Experimental}

\section{Materials}

Tetraethyl orthosilicate (TEOS, 98\%, Aldrich), nonionic triblock copolymer surfactant, Pluronic P123 (Aldrich), hydrochloric acid ( $\mathrm{HCl}, 37 \%$, Samchun)), ammonium per sulfate, $\left(\mathrm{NH}_{4}\right)_{2} \mathrm{~S}_{2} \mathrm{O}_{8}$ (Aldrich,), and technical grade ethanol (99\%, Samchun) were used without further purification. Aniline PA (Aldrich) was distilled before use. All the solutions were prepared with Puric-S grade deionized water $(\mathrm{R}=$ $2.0 \mathrm{M} \Omega$ :m, Organo Co., Tokyo).

\section{Synthesis of porous silica}

Porous silica was synthesized in acid medium ( $\mathrm{HCl}, 2.0 \mathrm{~mol}$ $\mathrm{dm}^{-3}$ ) using TEOS as precursor to silica. Non-ionic triblock copolymer surfactant, Pluronic P123 (poly (ethylene oxide)poly (propylene oxide)-poly (ethylene oxide)), $\mathrm{EO}_{20} \mathrm{PO}_{70} \mathrm{EO}_{20}$ was used as the structure-directing agent. In a typical reaction, $4.0 \mathrm{~g}$ of Pluronic P123 was dissolved in $30.0 \mathrm{~g}$ of water and $120.0 \mathrm{~g}$ of $37 \% \mathrm{HCl}$ under stirring condition at room temperature until a homogeneous mixture was obtained. Subsequently, $8.32 \mathrm{~g}$ of TEOS was added and the resulting mixture was stirred vigorously in an open beaker at $40^{\circ} \mathrm{C}$ for $24 \mathrm{~h}$. The resulting mixture was transferred to a polypropylene bottle and heated at $100^{\circ} \mathrm{C}$ for $20 \mathrm{~h}$ without stirring. The solid phase was then separated from the solution by filtration and washed with deionized water, dried at $80^{\circ} \mathrm{C}$ and calcined at $550^{\circ} \mathrm{C}$ for about $6 \mathrm{~h}$ under nitrogen atmosphere to burn out the surfactant

\section{Preparation of PAni-porous silica composite}

PAni-porous silica composites was prepared by emulsion polymerization method (Pedroso et al 2013). Initially, aniline was added to surfactant containing acidic porous silica dissolved in deionized water and the dispersion was stirred for $2 \mathrm{~h}$ at room temperature followed by drop wise addition of an aqueous solution of $\left(\mathrm{NH}_{4}\right)_{2} \mathrm{~S}_{2} \mathrm{O}_{8}$ (aniline and $\left(\mathrm{NH}_{4}\right)_{2} \mathrm{~S}_{2} \mathrm{O}_{8}$ molar ratio of $\left.1: 1\right)$ to initiate the polymerization. The reaction mixture was left overnight at room temperature under constant stirring. A dark green PAni- porous silica precipitate was isolated by filtration, washed several times with water and ethanol and dried at $80^{\circ} \mathrm{C}$ for $24 \mathrm{~h}$.

\section{Molecular characterization by FT-IR}

PAni and PAni-porous silica were analyzed by FT-IR spectrometer (Shimadzu FT-IR IR-Prestige-21) for molecular characterization. The FT-IR spectra of the samples were recorded in the region of $4000-500 \mathrm{~cm}^{-1}$ with $2 \mathrm{~cm}^{-1}$ resolution. Usually 32 scans were recorded.

Morphological characterization by SEM, TEM and TEM$E D X$

SEM images of porous silica and PAni-porous silica composite were obtained from a SEM (Hitachi S-4300) at an acceleration voltage of $20 \mathrm{kV}$. Transmission electron microscopic (TEM) measurements were conducted using a JEOL JEM-2100F electron microscope equipped with a chargecouple device (CCD) camera (Gatan Inc.). The accelerating voltage used was $200 \mathrm{kV}$. The TEM images were recorded at different magnifications which were calibrated using the lattice images of asbestos crystals. The energy dispersive X-ray (EDX) analysis of the samples was carried out by an Oxford, INCA, EDX micro analyzer (Model: 6853-H) attached to TEM.

\section{Surface analysis by BET method}

All the samples were characterized by nitrogen adsorptiondesorption isotherms at $77 \mathrm{~K}$ using BEL Sorp Max (BEL Japan Inc) equipment. Prior to the measurements all samples were degassed under vacuum at $105^{\circ} \mathrm{C}$ for $12 \mathrm{~h}$ using BEL Prep Vac II (BEL Japan Inc). Nitrogen adsorption/desorption isotherm and the pore size distribution were analyzed by $\mathrm{BJH}$ method using the desorption part of the isotherm and surface area were determined using the BET method. 


\section{Results and discussion}

Molecular characterization by FT-IR

Molecular characterization of the synthesized PAni-porous silica and PAni were carried out by FT-IR analyses. The observed bands assigned for different functional groups (Sharma 1993; Pavia et al 1979) present in the PAni-silica composite material and the reference bands are summarized in Table I.

It is interesting to note that molecular band position of PAniporous silica composite were similar to the previous report for PAni-silica composite materials (Akhtar et al 2012) (Table I).

\section{Morphological studies by SEM}

Morphologies of the silica were observed by a Hitachi- 4300 scanning electron microscope (SEM). One drop of the suspension in ethanol was deposited on a SEM sample holder and allowed to dry. The samples were then coated with Pt using a sputter-coater (EMITECH K550X) for $2 \mathrm{~min}$ at 30 $\mathrm{mA}$ for SEM imaging.

\section{Table I. Assignments of band positions in the FT-IR spectra of PAni-porous silica composite}

\begin{tabular}{lccc}
\hline $\begin{array}{l}\text { Functional } \\
\text { group }\end{array}$ & $\begin{array}{c}\text { Standard absorption* } \\
\text { band range }\left(\mathrm{cm}^{-1}\right)\end{array}$ & $\begin{array}{c}\text { Observed absorption } \\
\text { bands }\left(\mathrm{cm}^{-1}\right)\end{array}$ & Assignments \\
\hline O-H & $3650-3200$ & $3500-3400$ & O-H stretching vibration; Water may be present \\
N-H & $3500-3100$ & $3300-3200$ & Aromatic secondary amine may be present \\
$\mathrm{C}=\mathrm{C}$ & $1600-1450$ & $1525-1475$ & $\mathrm{C}=\mathrm{C}$ bond stretching in aromatic double bond \\
$\mathrm{C}-\mathrm{N}$ & $1350-1250$ & $1300-1250$ & $\mathrm{C}-\mathrm{N}$ stretching in aromatic amine \\
$\mathrm{C}=\mathrm{N}$ & $1700-1600$ & $1700-1600$ & $\mathrm{C}=\mathrm{N}$ stretching in imines \\
$\mathrm{C}-\mathrm{H}$ & $3000-2800$ & $3000-2850$ & $\mathrm{C}-\mathrm{H}$ stretching and C-H bending \\
& $900-690$ & $850-800$ & unsubstituted benzene \\
Si-O & $1111-801$ & $1100-1050$ & Presence of silica \\
\hline
\end{tabular}

* Sharma et al 1902 nud nonin n+ 1 1 n7n
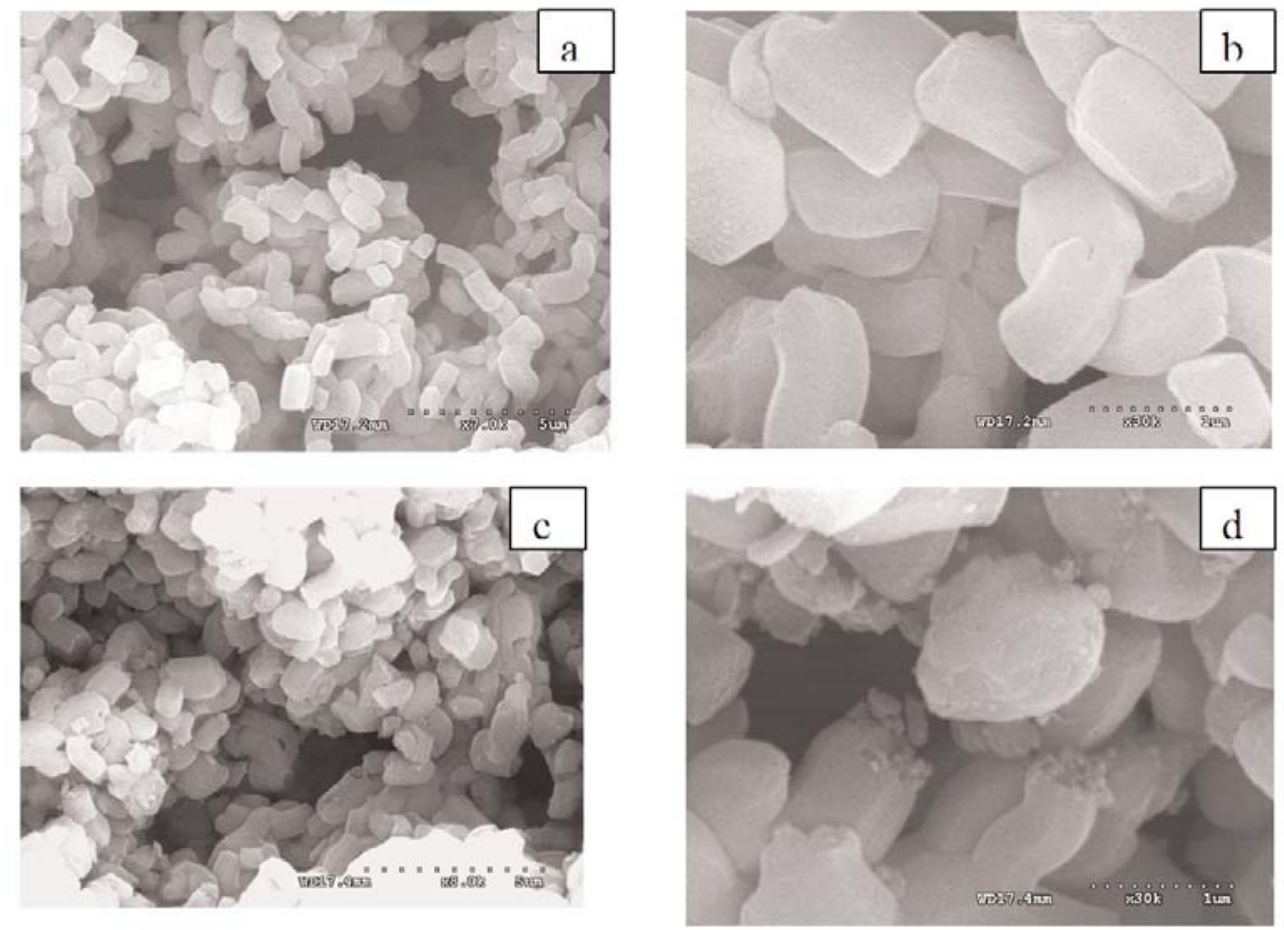

Fig. 1. SEM images of porous silica and PAni-porous silica composite.

$1 \mathrm{a}$ and $1 \mathrm{~b}$ were wide range, large area magnification and high mangnification of porous silica respectively. $1 \mathrm{c}$ and $1 \mathrm{~d}$ were wide range, large area magnification and high mangnification of PAni-silica composite respectively (scale bar for $\mathrm{a}$ and $\mathrm{c}$ were $5 \mu \mathrm{m}$ and $\mathrm{b}$ and $\mathrm{d}$ were $1 \mu \mathrm{m})$. 
The morphologies of synthesized porous silica are shown in Figs $1 \mathrm{a}$ and $1 \mathrm{~b}$ and those of PAni-porous silica composite are shown in Figs 1c and 1d. Close examination of the SEM images (Fig. 1a and 1b) clearly indicate that the silica particles have definite shapes and the surfaces are clean and smooth with apparently no impurities. The sizes of particles were around $1.0-1.5 \mu \mathrm{m}$ and the average diameter falls in the range of 300-500nm. Furthermore, SEM images (Fig. 1c and 1d) of the composites clearly show that the surfaces are uneven and that PAni are homogeneouly distributed and seems strongly bonded with porous silica.

\section{Morphology studies by TEM}

The porosity of silica was confirmed by TEM. The TEM images clearly indicate that prous silica has very uniform $2 \mathrm{~d}$ hexagonal pore and size of the pore was $c a .8 .0 \mathrm{~nm}$ in diameter as shown in Fig. 2a.
Table II. The elemental-atomic level composition of PAni-porous silica composite.

\begin{tabular}{lcc}
\hline Element & Weight $\%$ & Atomic $\%$ \\
\hline $\mathrm{C}$ & 16.40 & 29.04 \\
$\mathrm{~N}$ & 1.63 & 2.47 \\
$\mathrm{O}$ & 11.18 & 14.86 \\
$\mathrm{Si}$ & 70.79 & 53.62 \\
\hline
\end{tabular}

Nitrogen adsorption desorption isotherm and pore size distribution and surface area measurements

Nitrogen adsorption-desorption isotherm of porous silica (Fig. 3a) and PAni-silica composite (Fig. 3b) show representative Type-IV isotherms, which are characteristic of mesoporous materials with uniform pore structure. The isotherms show a sharp capillary condensation step at a relative pressure $\left(\mathrm{P} / \mathrm{P}_{\mathrm{o}}\right)$ of $0.6-0.75$, suggesting a narrow pore size distri-
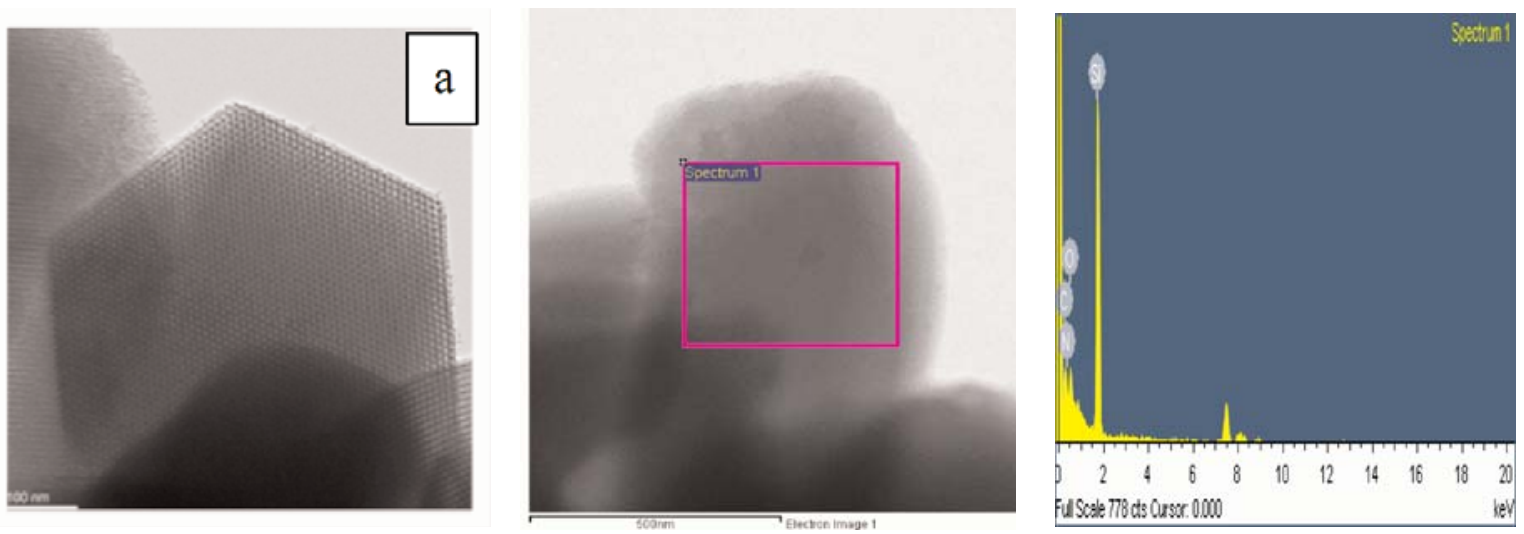

Fig. 2. Transmission electrom microscpic images of (a) porous silica (scale bar- 100nm, $\square$ ) (b)PAni-porous silica composite (scale bar-500nm, (compositional elements-N, C, O and Si).

PAni are well dispersed on /into in the porous silica surface and inside the pore which is shown as TEM images in Fig. 2b.The TEM images of PAni-porous silica composite is not clear because electron beam cannot penetrate well into lattice fringe of the composite since PAni is incorporated inside the silica pores. The well dispersion may be due to electrostatic attraction between the PAni and silica.The rectungular marker in Fig. 2b was used for elemental analysis by TEMEDX of PAni silica composite (Table I). Interestingly, the PAni is uniformly dispersed and bonded with silica pore that was clearly indentified by TEM EDX. Fig. 2c is the rectangular areas of Fig. $2 \mathrm{~b}$ and the elemetal mapping composition of the respective composite is presented in Table II. bution. The hysteresis loop is a typical H1 Type, implying a uniform cylindrical pore geometry.

The pore size of porous silica $(\sim 6.1 \mathrm{~nm})$ and PAni-porous silica composite $(\sim 7.5 \mathrm{~nm})$ were calculated from the respective adsorption data (Figs. $4 \mathrm{a}$ and $4 \mathrm{~b}$ ) using the BJH method. The specific BET surface area of porous silica was found to be as high as $850 \mathrm{~m}^{2} \mathrm{~g}^{-1}$. After incorporating PAni into the porous silica structure, the composite samples showed sharp capillary condensation steps at lower relative pressure of 0.55 0.70 , indicating smaller pore size. This may be due to the shrinking of framework during the incorporation of aniline but still remain a Type IV isotherm. The BET surface area of the composite was found to be $434.0 \mathrm{~m}^{2} \mathrm{~g}^{-1}$. In a previous 

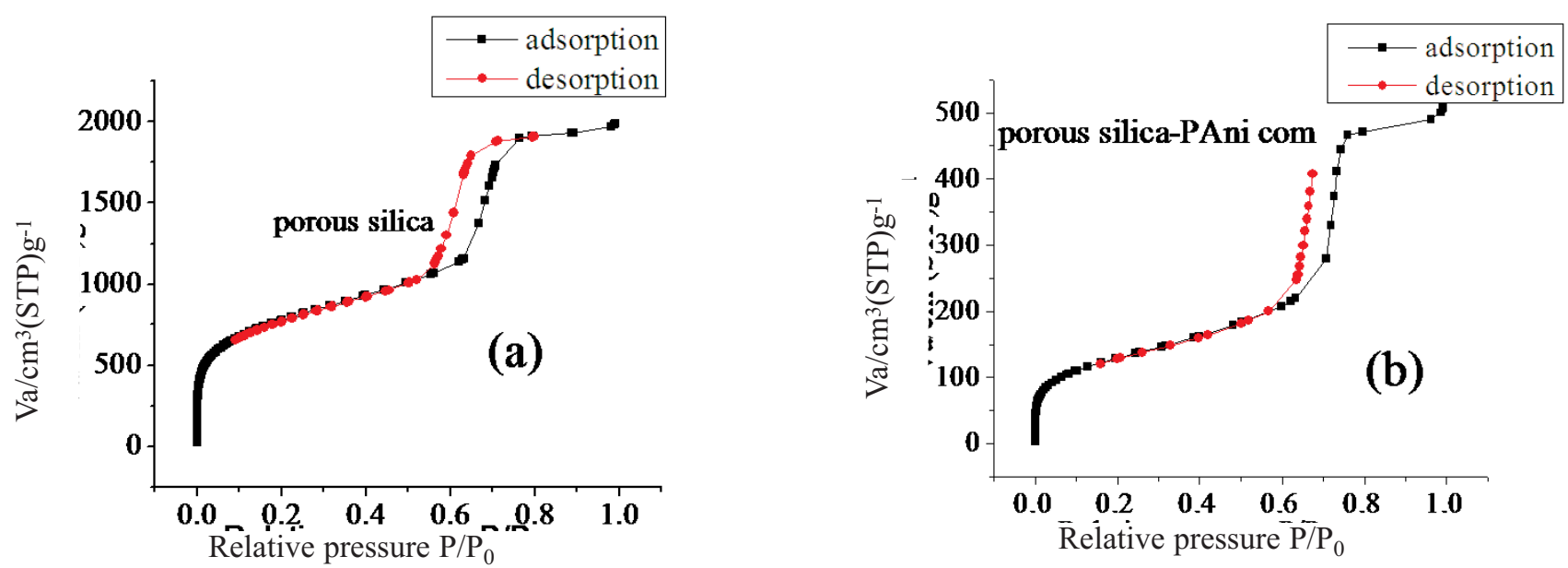

Fig. 3. Nitrogen adsorption-desorption isotherm of (a) porous silica and (b) PAni-porous silica composite.

study the surface areas of PAni and PAni /silica composite were reported as $41.5 \mathrm{~m}^{2} \mathrm{~g}^{-1}$ and $78.3 \mathrm{~m}^{2} \mathrm{~g}^{-1}$ respectively (Akhtar et al 2012). The surface area of the composite has, therefore, been increased by about $355.7 \mathrm{~m}^{2} \mathrm{~g}^{-1}$.

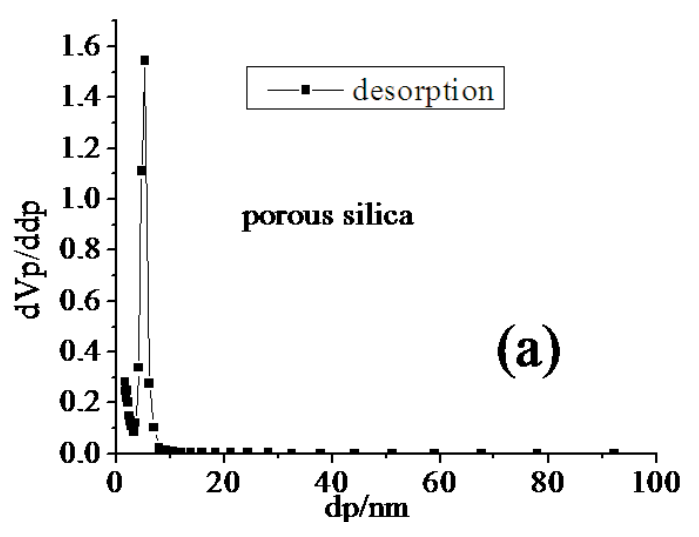

order is provided through balanced coulombic, hydrogen bonding, and van der Waals interactions (Chan. et al 2005).

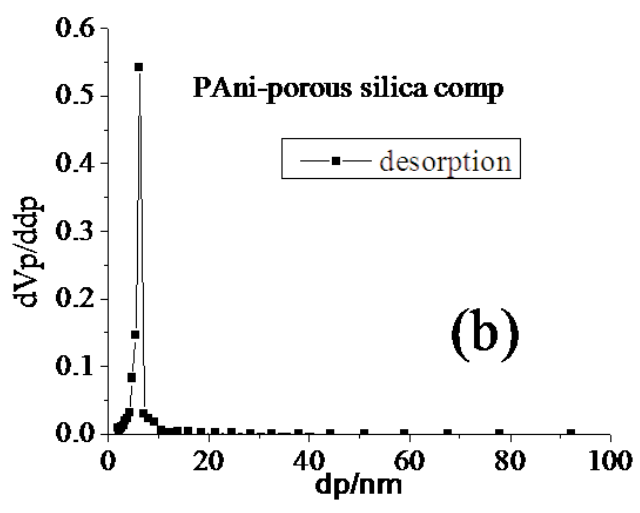

Fig. 4. Pore size distribution of (a) porous silica and (b) PAni-porous silica composite using desorption isotherm.

It is worth mentioning here that the mesoporosity still remains as such and Type IV isotherm was obtained and a typical hysteresis loop H1 implies uniform cylindrical pore geometry.

\section{Proposed mechanism of formation of porous silica}

Mesoporous ordering and final morphology are both influenced by the cooperative self-assembly of the inorganic and organic species present during the synthesis of porous silica (Beck et al 1992; Chan. et al 2005). Long range periodic
Above the critical micelle concentration $\left(0.03 \mathrm{wt} \%\right.$ at $\left.25^{\circ} \mathrm{C}\right)$, $\mathrm{P} 123$ is soluble in dilute solution in water (Wen et al 1999). As the temperature is raised above $15^{\circ} \mathrm{C}$, the hydrophobic polypropylene oxide( PPO) segments of the polymer becomes increasingly more hydrophobic and the copolymer spontaneously forms dynamic core-shell micelles with the more hydrophobic PPO segments in the core and the hydrophilic polyethylene oxide (PEO) segments making up the surrounding shell (Giaquinto et al 2008). Fig. 5 shows a simplified example of the Co-assembly process. 

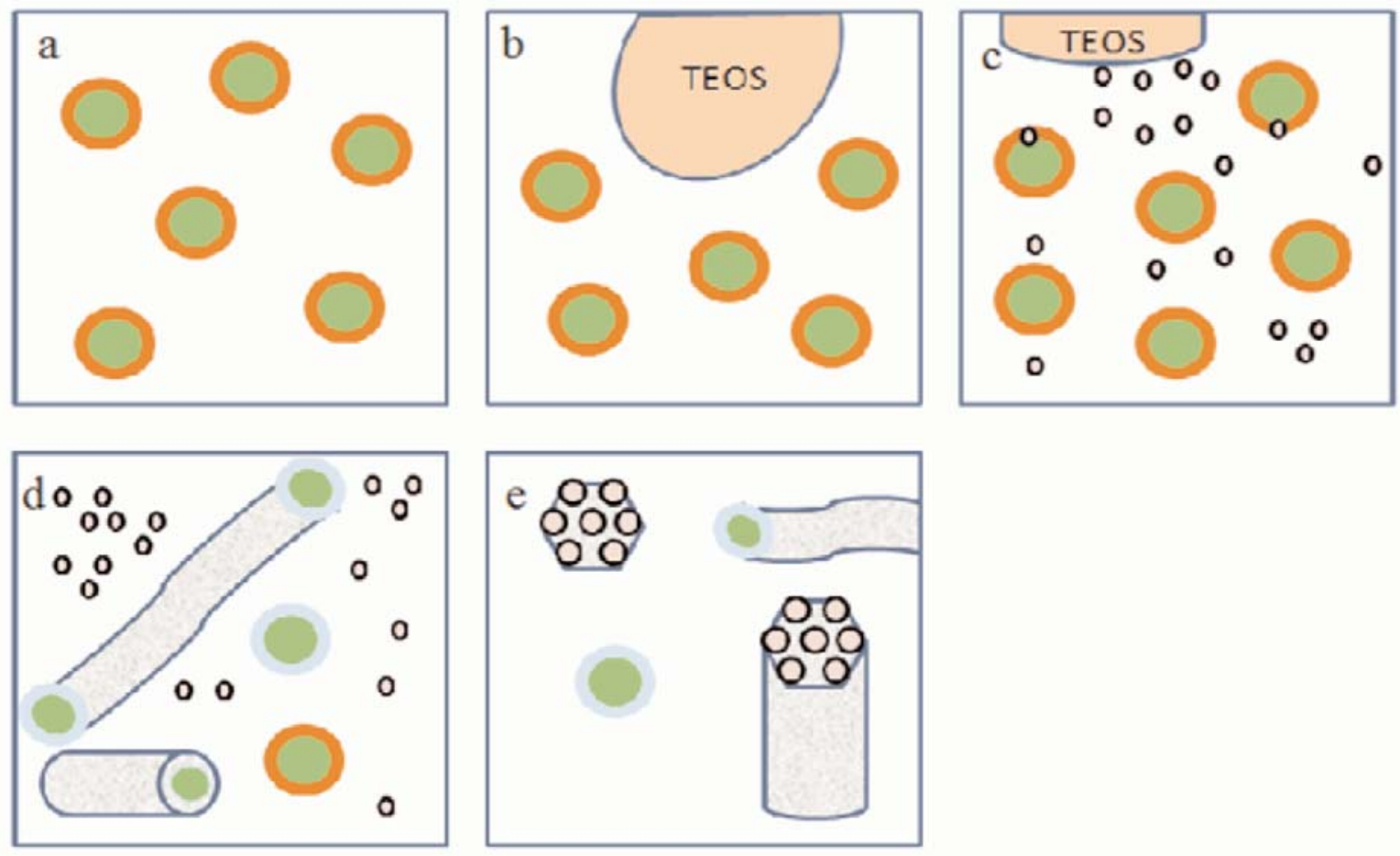

Fig. 5. Formation mechanism of the 2D-hexagonal porous silica

(a) initial solution of P123 spherical micelles, (b) addition of the TEOS silica precursor, (c) hydrolysis step and beginning of the condensation, (d) shape transformation of the hybrid organic-inorganic micelles from spherical to rod-like, (e) nucleation of the 2D-hexagonal phase.

The association of hydronium ions with the alkaline oxide groups corroborates the co-assembly of the P123 copolymer in acidic aqueous solutions. As a result, the long range columbic interaction is further enhanced (Chan. et al 2005). The silica precursor is positively charged at $\mathrm{pH} \sim 1$, and a cooperative self-assembly of the silica-block-copolymer rich meso-phase is expected to take place through an intermediate of the form $\left(\mathrm{SOH}^{+}\right)\left(\mathrm{X}-\mathrm{I}^{+}\right)(\mathrm{Che}$ et al 2005) as the cationic silica interacts preferentially through the halide anion present from the acidic modifier (Beck et al 1992; Chan. et al 2005).

\section{Conclusion}

In this study we have successfully synthesized porous silica with rod-like uniform morphology. Structure of the porous silica possess uniform $2 \mathrm{~d}$ hexagonal pore and unique pore size distribution, high surface area is $c a .850 \mathrm{~m}^{2} \mathrm{~g}^{-1}$ and average pore diameter of $6.1 \mathrm{~nm}$. The incorporation of PAni in and around the pore and the surface of silica was confirmed by TEM and TEM-EDX analyses. After incorporation of PAni inside the silica pore, the porous silica frame work shrinks and as a result pore size increase slightly although the framework of porous silica did not collapse. The surface area of the composite was found to be as high as $434 \mathrm{~m}^{2} \mathrm{~g}^{-1}$ which is 5.5 time higher than our previous report (surface area $78.3 \mathrm{~m}^{2} \mathrm{~g}^{-1}$; Akhter et al 2012). Both Porous silica and the composite samples show sharp capillary condensation of $\mathrm{N}_{2}$ adsorption-desorption isotherm at relative pressure 0.6 to 0.8. This, of course, means both samples had narrow pore size distribution and remain in Type IV isotherm and typical hysteresis loop H1 implying uniform cylindrical pore geometry.

\section{Acknowledgement}

The authors gratefully acknowledge the BCSIR authority who gave the chance to do this research. Authors also acknowledge kind support from instrumental analysis of the 
Centre for Nano Material, Sogang University, Korea Republic, for SEM, TEM, EDX and BET measurements.

\section{References}

Ahmed A, Clowes R, Elizabeth R, Myers WH and Zhang H (2010), Synthesis of uniform porous silica microspheres with hydrophilic polymer as stabilizing agent, I.\&EC. Res, 49: 602-608.

Akhtar US, Miran MS, Susan MABH, Mollah MYA, and Rahmana MM (2012), Preparation and characterization of polyaniline-silica composite material, Bangladesh J. Sci. Ind. Res. 47(3): 249-256.

Attard GS, Glyde JC and Göltner CG (1995), Liquid-crystalline phases as templates for the synthesis of mesoporous silica, Nature, 378: 366-368.

Bagshaw SA, Prouzet E and Pinnavaia TJ (1995), Templating of mesoporous molecular sieves by nonionic polyethylene oxide surfactants, Science, 269: 1242-1245.

Baochen W, Gi L, Changzhi L and Fosong W (1988), Largescale synthesis of polyaniline batteries, J. Power Sources 24: 115-120.

Beck JS, Vartuli JC, Roth WJ, Leonowicz ME, Kresge CT, Schmitt KD, Chu CT, Olson DH, Sheppard EW, McCullen CT, Higgins JB and Schlenker JL (1992), A new family of mesoporous molecular sieves prepared with liquid crystal templates, J. Am. Chem. Soc. 114: 10834-10843.

Bhadra D, Khastgir NK, Singha J and Lee H (2009), Progress in preparation, processing and applications of polyaniline, Prog. in Poly. Sci. 34: 783-810.

Chan F, Yeung LS, LoBrutto R and Kazakevich YV (2005), Characterization of phenyl-type HPLC adsorbents, $J$. Chrom. A, 1069: 217-224

Che S, Li H, Lim S, Sakamoto Y, Terasaki O and Tatsumi T (2005), Synthesis mechanism of cationic surfactant templating mesoporous silica under an acidic synthesis process, Chem. Mater., 17: 4103-4113
Djuradoa D, Eeb MB, Gonzalezb M, Mondellib C, Dufourc B, Rannouc P, Pronc A and Travers JP (2003), Molecular dynamics in plastic conducting compounds of polyaniline, J. Chem. Phy. 292: 355-361.

Faez F, Rezende MC and Martin IM (2000), Intrinsically conducting polymers and their potential in electromagnetic interference shielding, Ciencia e Tecnologia, 10: 130-137.

Giaquinto A, Liu X, Bach A and Kazakevich Y (2008), Surface area of reversed-phase HPLC columns, Anal Chem. 80 (16): 6358-6364.

Johansson EM, Mohamed A, Ballem MA, Jose M, Ordoba C and Oden M (2011), Rapid synthesis of SBA-15 rods with variable lengths, widths, and tunable large pores, Langmuir 27: 4994-4999.

Kruk M and Jaroniec M (2000), Characterization of the porous structure of SBA-15, Chem. Mater. 12:19611968.

Li D, Huang J and Kaner RB (2009), Polyaniline nano fibers: a unique polymer nanostructure for versatile applications. Acc. Chem. Res. 42:135-145.

Pavia DL, Lampman GM and Kriz GS (1979), Introduction of spectroscopy, Saunder College Publishing, USA.

Pedroso CCS, Junqueira V, Rubinger CPL, Martins TS and Faez R (2013), Preparation, characterization and electrical conduction mechanism of polyaniline/ordered mesoporous silica composites. Syn. Metals 170:11-18.

Sharma YR (1993), Elementary organic spectroscopy. S. Chand. Company Ltd., New Delhi, India, p 80.

Sujandi Park SE, Han D, Han S, Jin MJ and Ohsuna T (2006), Amino-functionalized SBA-15 type mesoporous silica having nanostructured hexagonal platelet morphology. Chem.Commun. 4131-4133.

Wang T, He J, Sun DY, Guo Y, Ma Y, Hu Y, Li G, Xue H, Tang J and Sun X (2011), Synthesis of mesoporous carbon-silica-polyaniline and nitrogen-containing carbonsilica films and their corrosion behavior in simulated proton exchange membrane fuel cells environment. $J$. Power Sources, 196: 9552-9560. 
Wen E, Asiaie R and Horvath CS. (1999), Dynamics of capillary elctrochromatography II. comparison of column efficiency parameters in microscale high-performance liquid chromatography and capillary electrochromatography, J. Chrom. A, 855: 349-366.

Xie D, Jiang Y, Pan W, Li D, Wu Z and Li Y (2002), Fabrication and characterization of polyaniline based gas sensors by ultrathin film technology, Sensors and Actuators B 81:158-164.

Zhang WL, Liu YD and Choi HJ (2012), Fabrication of semiconducting graphene oxide/polyaniline composite particles and their electrorheological response under an applied electric field, Carbon, 50: 290-296.
Zhao D, Huo Q, Feng J, Chmelka BF and Stucky GD (1998), Nonionic triblock and star diblock copolymer and oligomeric surfactant syntheses of highly ordered, hydrothermally stable, mesoporous silica structures, $J$. Am. Chem. Soc.120: 6024-6036.

Zhao D, Feng J, Huo Q, Melosh N, Glenn HF, Bradley FC and Galen DS (1998), Triblock copolymer syntheses of mesoporous silica with periodic 50 to 300 Angstrom pores, Science, 279: 548-552.

Received: 03 September 2013; Revised: 09 February 2014; Accepted: 02 March 2014. 